\title{
New Insights into Cluster Headache
}

\author{
An expert interview with Nunu Lund \\ University of Copenhagen, Copenhagen, Denmark
}

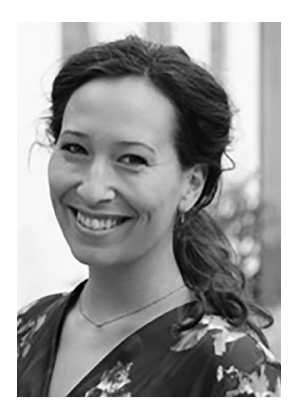

DOl: https://doi.org/10.17925/ENR.2018.13.2.68

\section{Nunu Lund}

Nunu Lund obtained her medical degree in 2014 at the University of Copenhagen, Denmark. She started her work with patients with cluster headache during a research year in 2012. After obtaining her medical degree, she was enrolled as a PhD student at the Danish Headache Center in the Cluster Headache Group supervised by Professor Rigmor Jensen and Mads Barloese. She has just finished her PhD project that includes studies on gender-differences, lifestyle factors and sleep in cluster headache patients and expects to defend it in the beginning of 2019.

\section{Keywords}

Cluster headache, chronobiology, epidemiology

Disclosure: Dr Lund has no conflicts no interest to declare in relation to this interview.

Review process: This is an expert interview and as such has not undergone the journal's usual peer review process, but has been approved by the Editorial Board.

Acknowledgements: Medical writing assistance was provided by Katrina Mountfort of Touch Medical Media.

Authorship: The named author meets the International Committee of Medical Journal Editors (ICMJE) criteria for authorship of this manuscript, takes responsibility for the integrity of the work as a whole, and has given final approval to the version to be published.

open Access: This article is published under the Creative Commons Attribution Noncommercial License, which permits any non-commercial use, distribution, adaptation, and reproduction provided the original author(s) and source are given appropriate credit. () The Authors 2018.

Received: 29 November 2018

Accepted: 3 December 2018

Citation: European Neurological Review. 2018;13(2):68-9

Corresponding Author: Nunu Lund, The Danish Headache Center, Department of Neurology,

Rigshospitalet-Glostrup, University of Copenhagen,

Copenhagen, Denmark.

E: nunu.laura.timotheussen.lund@regionh.dk

Support: No funding was received for

the publication of this article.
C luster headache $(\mathrm{CH})$ is a primary headache disorder affecting up to $0.1 \%$ of the population.' It is characterised by the extreme nature of the attacks, the unilateral distribution of pain and the accompanying ipsilateral autonomic symptoms and restlessness. ${ }^{2}$ Attacks may arise between once every other day and eight times a day during the attack periods, the bouts, and patients are highly burdened and disabled. ${ }^{3}$ Although the clinical features are distinct, $\mathrm{CH}$ may be misdiagnosed, and is suboptimally managed. In an expert interview, Nunu Lund discusses the unmet needs in the management of $\mathrm{CH}$, as well as the findings of a recent study that may improve the diagnosis and management of this debilitating condition.

\section{Q. What are the major unmet needs in the management of cluster headache?}

The major unmet need is specific and effective treatment developed for $\mathrm{CH}$, as regular painkillers are ineffective. Currently, attacks are treated with inhaled high-flow oxygen or injectable triptans. To lower attack frequency and/or severity, preventive treatment with verapamil or lithium is used in high dosages and therefore often lead to side effects. Antibodies targeting the signal molecule calcitonin gene-related peptide or its receptor are examples of upcoming specific drugs and headache specialists await the trial results with excitement.

Another unmet need in $\mathrm{CH}$ is to determine the pathophysiology behind factors that trigger the attacks. Sleep or sleep-related diseases, such as sleep apnoea, have been proposed, but three recent studies from our group seem to exclude such a simplicity. ${ }^{4-6}$ In most patients, attacks occur with a striking rhythmicity, indicating that the hypothalamus and especially areas linked to the suprachiasmatic nucleus (our master clock) are involved. ${ }^{6,7}$

\section{Q. Cluster headaches were originally considered to be almost exclusive to men but it is now known that a substantial proportion of women suffer from cluster headaches. What is the reason for this change?}

Interestingly, and for unknown reasons, the reported male:female ratios have decreased over the years from 18-20:1 in the 1980s to 3.5:1 in the more recent studies and now 2:1 in a UK and Danish study. ${ }^{8-10}$ Different hypotheses have been suggested to explain the decrease over the years. Changes in the lifestyle of women, especially in relation to smoking, has been suggested to result in an increased prevalence of $\mathrm{CH}$ in women. ${ }^{11}$ Smoking is interesting due to the consistently high prevalence of smokers among patients with $\mathrm{CH}$. Therefore, it has been suggested that smoking is causally related to $\mathrm{CH}$, yet the evidence is not convincing. Overall, the prevalence of smokers 
(in both sexes) is decreasing, as in the general population, and may therefore not fully explain the increasing prevalence in women. Therefore, an increased awareness and thereby a more accurate diagnosis may better account for the findings.

\section{Q. Could you tell us a little about the aims and design of your recent study investigating differences between the sexes in the phenotype of cluster headache?}

The study had two aims: firstly, to describe and compare the clinical characteristics in men and women in relation to misdiagnosis, diagnostic delay and sector of diagnosis. Secondly, to describe the attack distribution over the day (the chronorisk) for men and women.

Data was derived from the Danish Cluster Headache Survey, a questionnaire-based survey that was initiated in 2012 and continuously recruited patients and controls until it was completed in 2017. It consisted of a broad variety of questions on demography, $\mathrm{CH}$ diagnosis and characterisation, $\mathrm{CH}$ burden, sleep, lifestyle, treatment of $\mathrm{CH}$ and other diseases, and physical activity. It took patients approximately 1 hour to complete. A semi-structured interview verifying the diagnosis and clearing ambiguities was performed. Patients with $\mathrm{CH}$ were diagnosed by headache specialists according to the International Classification of Headache Disorders II. ${ }^{12}$

\section{Q. What were the findings of this study in terms of the chronobiology of cluster headache?}

In total, 351 patients participated, of which 235 were men and 116 were women. The chronorisk for all patients was highest between 1 am and $3 \mathrm{am}$. Interestingly, the chronorisk distribution differed between the sexes. The highest risks of attacks occurred approximately 1 hour later for women than for men $(p<0.05)$, a difference that could not be fully explained by a longer self-reported sleep latency in women than in men (for patients with attacks within the last month). ${ }^{7}$

In a recently published study from our group, it was shown that phenotype (being episodic or chronic), preventive treatment with verapamil, and lifestyle factors also affected the chronorisk distribution in patients with $\mathrm{CH} .{ }^{7}$ These results imply that the trigger of $\mathrm{CH}$ attacks is multifactorial.

Besides giving insights on the pathophysiology of $\mathrm{CH}$, one way to apply the current knowledge could be to study whether the treatment could be optimised according to the identified risk in patients. In $\mathrm{CH}$, individualised treatment with timing of administration according to attack risk could be an exciting way to improve treatment efficacy.

\section{Q. What were the findings of this study in terms of the clinical presentation of cluster headache and what are the clinical implications of these findings?}

To our surprise, our results showed that there were only few and minor differences in the clinical presentation of $\mathrm{CH}$ in men and women. ${ }^{10}$ Women should therefore, in theory, be as recognisable as men in all sectors of the healthcare system, including the primary and secondary sectors. However, our data indicated that this was not the case. Misdiagnosis was significantly more frequent in women, and twice as many women did not receive the correct diagnosis until seen in a tertiary headache centre. ${ }^{\text {The }}$ consequences of misdiagnosis are likely to be incorrect management, and ultimately, unnecessary suffering.

Migraine-like symptoms in the form of photophobia, phonophobia, nausea and vomiting could very likely complicate the diagnostic process and explain part of our observations. An already existing migraine disorder could possibly also influence the diagnostic process. We found that the prevalence of migraine in women resembled that of the general population; ${ }^{10}$ nevertheless, migraine remains to be more prevalent in women than in men. Hypothetically, medical doctors could be reluctant to add a second headache diagnosis, i.e. both migraine and $\mathrm{CH}$ - if true, this could contribute as well.

Better headache education for medical doctors, as well as more public awareness, are essential to minimise diagnostic delay, misdiagnosis and mistreatment of cluster headache for both sexes. $\square$
1. Fischera M, Marziniak M, Gralow I, et al. The incidence and prevalence of cluster headache: a meta-analysis of population-based studies. Cephalalgia. 2008;28:614-8.

2. Headache Classification Committee of the International Headache Society (IHS) The International Classification of Headache Disorders, 3rd edition. Cephalalgia. 2018;38:1-211.

3. Jensen RM, Lyngberg A, Jensen RH. Burden of cluster headache Cephalalgia. 2007;27:535-41.

4. Barloese MCJ, Jennum PJ, Lund NT, et al. Sleep in cluster headache - beyond a temporal rapid eye movement relationship? Eur J Neurol. 2015;22:656-e40.

5. Lund NLT, Snoer AH, Petersen AS, et al. Disturbed sleep in cluster headache is not the result of transient processes associated with the cluster period. Eur I Neurol. 2018: [ePub ahead of print]. DOI: 10.1111/ene.13820

6. Lund NLT, Snoer AH, Jennum PJ, et al. Sleep in cluster headache revisited: Results from a controlled actigraphic study. Cephalalgia. 2018: [ePub ahead of print]. DOI: $10.1177 / 0333102418815506$.

7. Barloese $M$, Haddock B, Lund NT, et al. Chronorisk in cluster headache: A tool for individualised therapy? Cephalalgia. 2018;38:2058-67.

8. Ekbom K, Svensson DA, Träff H, et al. Age at onset and sex ratio in cluster headache: observations over three decades.
Cephalalgia 2002:22:94-100

9. Bahra A, May A, Goadsby PJ. Cluster headache: a prospective clinical study with diagnostic implications. Neurology. 2002; 12:58:354-61

10. Lund $N$, Barloese M, Petersen A, et al. Chronobiology differs between men and women with cluster headache, clinical phenotype does not. Neurology. 2017;88:1069-76.

11. Manzoni GC. Gender ratio of cluster headache over the years: a possible role of changes in lifestyle. Cephalalgia. 1998;18:138-42.

12. Headache Classification Committee of the International Headache Society. The International Classification of Headache Disorders 2nd ed. Cephalalgia. 2004;24 Suppl. 1:1-160. 